\title{
JM
}

Volume 6 No. 1 (April 2018)

(C) The Author(s)

\section{GAMBARAN PENGETAHUAN IBU DAN SUAMI TENTANG PERUBAHAN FISIK DAN PSIKOLOGIS SAAT HAMIL DI WILAYAH KERJA PUSKESMAS BERINGIN RAYA KOTA BENGKULUTAHUN 2016}

\author{
DESCRIPTION OF UNDERSTANDING OF MOTHER AND HUSBAND TOWARD \\ PHYSICAL AND PSYCHOLOGICAL CHANGES DURING PREGNANCY IN \\ WORKING AREA OF BERINGIN RAYA PUBLIC HEALTH \\ CENTER BENGKULU
}

\author{
LUCKY NELAZYANI, NAILUL HIKMI \\ DOSEN PRODI DIPLOMA III KEBIDANAN FIKES UNIVED BENGKULU \\ Email : Luckynelazyani@yahoo.co.id
}

\begin{abstract}
ABSTRAK
Kehamilan melibatkan berbagai perubahan fisik dan perubahan psikologis. Kehamilan pada umumnya berkembang dengan normal, namun kadang tidak sesuai dengan yang diharapkan, sulit diprediksi apakah ibu hamil akan bermasalah selama kehamilan atau baik-baik saja. Maka dari itu pengetahuan ibu dan suami dalam menghadapi perubahan fisik maupun psikologis merupakan hal yang sangat penting. Penelitian ini bertujuan untuk mengetahui gambaran pengetahuan ibu dan suami tentang perubahan fisik dan psikologis saat hamil Di Wilayah Kerja UPTD Puskesmas Beringin Raya kota Bengkulu Tahun 2016.Metode penelitian yang digunakan dalam penelitian ini adalah penelitian secara deskriptif, dengan jumlah 82 responden ibu hamil dan 82 responden suami diambil dengan teknik Purposive sampling. Jenis data yang digunakan dalam penelitian ini menggunakan data primer dan dianalisis menggunakan analisis univariat.Lebih dari setengah ibu hamil $(56,1 \%)$, mempunyai pengetahuan kurang tentang perubahan fisiologis saat hamil, hampir sebagian ibu hamil (46,3\%), mempunyai pengetahuan baik tentang perubahan psikologi saat hamil. lebih dari setengah suami hamil $(56,1 \%)$, mempunyai pengetahuan kurang tentang perubahan fisiologis ibu hamil dan setengah suami hamil (50,0\%), mempunyai pengetahuan kurang tentang perubahan psikologi ibu hamil.Pengetahuan ibu hamil dan istri tentang perubahan fisik dan psikologis dalam kategori kurang. kepada pihak Puskesmas Beringin Raya Kota Bengkulu dapat lebih meningkatkan dalam memberikan penyuluhan kepada ibu hamil sehingga meningkatkan pengetahuan ibu hamil.
\end{abstract}

Kata kunci: pengetahuan perubahan fisik dan psikologis ibu hamil

\begin{abstract}
Pregnancy involved various physical and psychological changes. Pregnancy usually develop normally, but sometimes not as expected, it was difficult to predict whether pregnant women could be problematic during pregnancy or fine. Thus the understanding of the mother and husband in the face of physical and psychological changes was very important. This study aimed to describe the understanding of mother and husband toward physical and psychological changes during pregnancy in working area of Beringin Raya Public Health Center Bengkulu
\end{abstract}


2016.The method used in this research was a descriptive study, with the number of respondents 82 pregnant women and 82 respondents husband was taken with purposive sampling technique. Data used in this study using primary data and analyzed using univariate analysis.More than half of pregnant women $(56.1 \%)$, had less understanding about the physiological changes during pregnancy, most pregnant women (46.3\%), had a good understanding about the physiological changes during pregnancy. more than half of pregnant husband (56.1\%), had less understanding about the physiological changes in pregnant women and pregnant husband half $(50.0 \%)$, had less understanding about the physiological changes of pregnant women.Expectant mothers and wives understanding about physical and psychological changes in the poor category. Beringin Raya Public Health Center Bengkulu could further increase in outreach to pregnant women thus increasing understanding of pregnant women.

\section{Keywords: Understanding, Physical and Psychological Changes, Pregnant Mother}

\section{PENDAHULUAN}

\section{Menurut World Health Organitation} (WHO), pada tahun 2012, sebanyak 585.000 perempuan meninggal saat hamil atau persalinan. Sebanyak 99\% kematian ibu akibat masalah persalinan atau kelahiran terjadi di negara-negara berkembang. Rasio kematian ibu di negara-negara berkembang merupakan tertinggi dan 450 kematian ibu per 100 ribu kelahiran bayi hidup jika dibandingkan dengan rasio kematian ibu di 9/100.000 negara persemakmuran (Depkes RI, 2012).

Angka kematian ibu (AKI) berdasarkan rumusan sustainable Development Goals atau (SDGs) tahun 2015-2019 yaitu target penurunan AKI secara global pada tahun 2030 adalah 70 kematian per 100.000 kelahiran hidup (Kemenkes, 2015). Angka kematian ibu di negara-negara Association Of South East Asia Nations (ASEAN) AKI indonesia tertinggi di negara ASEAN yaitu berdasarkan laporan RPJMN rata-rata AKI tercatat mencapai 306 per 100.000 hidup dan AKI yang terendah yaitu Singapura 24 per 100.000 kelahiran hidup (RPJMN, 2015).

Target Millennium Development Gols (MDGs) 5 yaitu menurunkan Aki menjadi 102/100.000 pada tahun 2015 masih memerlukan upaya khusus dan kerja keras dari segala pihak baik pemerintah maupun masyarakat. Angka kematian ibu yang tinggi menunjukan rawannya derajat kesehatan ibu. AKI menjadi salah satu indikator penting dalam menentukan derajat kesehatan masyarakat. AKI menggambarkan jumlah wanita yang meningggal dari suatu penyebab kematian terkait dengan gangguan kehamilan atau penangannannya (tidak termasuk kecelakaan atau kasus insidentil) selama kehamilan per 100.000 kelahiran hidup (Riskesdas, 2013)

Berdasarkan Survei Demografi dan kesehatan indonesia (SDKI) tahun 20122013, angka kematian ibu sebesar 359 / 100.000 kelahiran hidup.Angka ini masih cukup tinggi apalagi jika di bandingkan dengan negara-negara tetangga.

Kehamilan melibatkan berbagai perubahan fisikologis antara lain perubahan fisik, perubahan sistem pencernaan, perubahan ovarium, payudara, sistem perkemihan, perubahan kenaikan berat badan, mual dan muntah sakit kepala dan keram pada perut. Kehamilan pada umumnya berkembang dengan normal, namun kadang tidak sesuai dengan yang diharapkan, sulit diprediksi apakah ibu hamil akan bermasalah selama kehamilan atau baik-baik saja (Prawirohardjo, 2006).

Jika kehamilan terjadi, berbagai macam efek terjadi dalam tubuh wanita. Selain perubahan fisik, wanita hamil juga akan mengalami perubahan psikologis yaitu, rasa tidak nyaman timbul kembali, merasa dirinya jelek, aneh, dan tidak menarik. Ibu merasa tidak menyenangkan ketika bayi tidak lahir tepat waktu. Ibu takut akan rasa sakit dan bahaya fisik yang timbul pada saat melahirkan, khawatir akan keselamatannya. Ibu khawatir bayi akan di lahirkan dalam 
keadaan tidak normal. Merasa sedih karena terpisah dari bayinya. Ibu merasa kehilangan perhatian. Ibu memiliki perasaan yang mudah terluka (sensitif). Libido menurun.

Peran suami yang mempunyai istri dalam masa kehamilan dapat lebih memahami tentang pentingnya berpartisipasi dalam masa kehamilan untuk mendukung kelancaran dan kesehatan ibu selama hamil dengan cara selalu menemani istri kunjungan periksa hamil dan mendengarkan setiap keluh kesah istri selama masa kehamilan. Sering sekali, seorang wanita mengatakan betapa bahagia akan menjadi seorang ibu. Namun tidak jarang juga ada wanita yang merasa khawatir dengan kehamilannya. Khawatir akan kehilangan kecantikan atau kemungkinan bayinya tidak normal (Dewi dkk, 2011).

Ketika proses kehamilan berlangsung akan terjadi perubahan fisik dan mental yang bersifat alami. Agar proses kehamilan berjalan normal, maka ibu hamil harus menjaga kesehatannya, dengan memperhatikan pola makan, gaya hidup dan aktifitas fisiknya. Kebutuhan ibu hamil akan nutrisi lebih tinggi dibandingkan saat sebelum hamil. kecakupan gizi ibu hamil dan pertumbuhan kandungannya dapat di ukur berdasarkan kenaikan berat badanya. Untuk memenuhi kebutuhan akan nutrisi, maka ibu harus makan-makanan yang banyak mengandung gizi karena makanan tersebut di perlukan untuk pertumbuhan janin, plasenta, buah dada dan kenaikan metabolisme. Apabila kekurangan dapat menyebabkan terjadinya abortus. (Dewi dkk, 2011) .

Berdasarkan hasil Survei Dasar Kesehatan Indonesia (SDKI) 2012 angka kematian ibu di Bengkulu 220 per 100.000 kelahiran hidup, meskipun sudah di bawah AKI nasional, tetapi masih jauh untuk mencapai target MDGs yaitu 102 per 100 ribu kelahiran hidup pada tahun 2015. Kota Bengkulu sudah mampu menaikan cakupan kunjungan ibu hamil setiap tahunnya, tetapi AKI masih jauh dari target MDGs.

Berdasarkan dari dinas Kesehatan Kota Bengkulu tahun 2014 cakupan KI sebesar 6,839 dengan jumlah sasaran ibu hamil 7,093 ibu hamil. Cakupan K1 tertinggi di Puskesmas Beringin Raya pada tahun 2014 sebesar 485, sedangkan cakupan K1 yang terendah di Puskesmas Padang Serai sebesar 287. Salah satu rencana strategis pemerintah melalui Departemen Kesehatan adalah menurunkan angka kematian ibu menjadi 118 per 100.000 kelahiran hidup pada tahun 2014 (BKKBN, 2012). Untuk mencapai misi tersebut di laksanakanlah program yang salah satunya adalah program Making Pregnancy Saver (MPS) dimana di harapkan bahwa dalam setiap persalinan, akan terjadi persalinan yang berlangsung aman, bayi yang akan di lahirkan hidup dan sehat (Depkes RI,2010).

Berdasarkan survey awal yang di lakukan di Puskesmas Beringin Raya, selama 2 hari, dan berdasarkan data rekap laporan KIA ibu hamil dari bulan Januari-Desember 2015 terdapat KI 462 ibu hamil dan K4 462 ibu hamil. Ada 3 orang ibu hamil dan suami yang telah di wawancarai. Semua ibu hamil dan suami yang diwawancarai masih banyak yang belum mengetahui tentang perubahan fisiologis pada kehamilan seperti perubahan uterus membesar, terjadi varises dan odema, sering kencing, mual muntah di awal kehamilan, dan perut membesar retak retak dan terdapat garis hitam memanjang, payudara membesar dan tegang, dan kenaikan berat badan, sedangkan perubahan psikologis pada kehamilan seperti rasa tidak nyaman timbul kembali, merasa dirinya jelek, aneh, dan tidak menarik. Ibu merasa tidak menyenangkan ketika bayi tidak lahir tepat waktu. Ibu takut akan rasa sakit dan bahaya fisik yang timbul pada saat melahirkan, khawatir akan keselamatannya. Ibu khawatir bayi akan di lahirkan dalam keadaan tidak normal. Merasa sedih karena terpisah dari bayinya. Ibu merasa kehilangan perhatian. Ibu memiliki perasaan yang mudah terluka (sensitif) Libido menurun. Dari latar belakang di atas peneliti tertarik untuk meneliti tentang pengetahuan ibu dan suami tentang perubahan fisik dan psikologis saat hamil 


\section{TUJUAN PENELITIAN}

1. Tujuan umum

Diketahuinya gambaran pengetahuan ibu dan suami tentang perubahan fisik dan psikologis saat hamil Di Wilayah Kerja UPTD Puskesmas Beringin Raya kota Bengkulu Tahun 2016

2. Tujuan khusus

a. Diketahui gambaran pengetahuan ibu hamil tentang perubahan fisik saat hamil Di Wilayah Kerja UPTD Puskesmas Beringin Raya Kota Bengkulu.

b. Diketahui gambaran pengetahuan ibu hamil tentang perubahan psikologis saat hamil Di Wilayah Kerja UPTD Puskesmas Beringin Raya Kota Bengkulu.

c. Diketahui gambaran pengetahuan suami tentang perubahan fisik ibu hamil Di Wilayah Kerja UPTD Puskesmas Beringin Raya Kota Bengkulu.

d. Diketahui Gambaran Pengetahuan Suami Tentang Perubahan psikologis ibu hamil Di Wilayah Kerja UPTD Puskesmas Beringin Raya Kota Bengkulu.

\section{METODE PENELITIAN}

Penelitian ini merupakan jenis penelitian deskriptif dengan tujuan untuk mengetahui gambaran perubahan fisiologis dan psikologis ibu hamil di wilayah kerja UPTD Puskesmas Beringin Raya Kota Bengkulu. Penelitian deskriptif adalah penelitian yang bertujuan untuk mengambarkan keadaan variabel yang di teliti (Notoatmodjo, 2010)

\section{HASIL PENELITIAN}

Analisis data dalam penelitian ini mengunakan analisis univariat untuk melihat distribusi frekuensi variabel penelitian yaitu pengetahuan istri dan suami tentang perubahan fisiologi dan psikologi pada ibu hamil, hasil analisis data tersebut dapat dilihat pada tabel berikut:

Tabel 1. Distribusi Frekuensi Pengetahuan Ibu Hamil Tentang Perubahan Fisik Dan Psikologis Saat Hamil di wilayah kerja UPTD Puskesmas Beringin Raya Kota Bengkulu tahun 2016

\begin{tabular}{ccc}
\hline $\begin{array}{c}\text { Pengetahuan Ibu } \\
\text { Hamil }\end{array}$ & $\begin{array}{c}\text { Frekuensi } \\
\text { (f) }\end{array}$ & $\begin{array}{c}\text { Persentase } \\
(\%)\end{array}$ \\
\hline Pengetahuan Fisiologi & & \\
\hline Baik & 21 & 25,6 \\
\hline Cukup & 15 & 18,3 \\
\hline Kurang & 46 & 56,1 \\
\hline Jumlah & 82 & 100,0 \\
\hline $\begin{array}{c}\text { Pengetahuan } \\
\text { Psikologgis }\end{array}$ & \\
\hline Baik & 38 & 46,3 \\
\hline Cukup & 28 & 34,1 \\
\hline Kurang & 16 & 19,5 \\
\hline Jumlah & 82 & 100,0 \\
\hline & &
\end{tabular}

Berdasarkan tabel 1 diatas menunjukkan bahwa lebih dari setengah ibu hamil (56,1\%), mempunyai pengetahuan kurang tentang perubahan fisiologis saat hamil, dan hampir sebagian ibu hamil $(46,3 \%)$, mempunyai pengetahuan baik tentang perubahan psikologi saat hamil.

Tabel 2. Distribusi Frekuensi Pengetahuan Suami Tentang Perubahan Fisik Dan Psikologis Saat Hamil di wilayah kerja UPTD Puskesmas Beringin Raya Kota Bengkulu tahun 2016

\begin{tabular}{ccc}
\hline Pengetahuan Suami & $\begin{array}{c}\text { Frekuensi } \\
\text { (f) }\end{array}$ & $\begin{array}{c}\text { Persentase } \\
\text { (\%) }\end{array}$ \\
\hline Pengetahuan Fisiologi & & \\
\hline Baik & 14 & 17,1 \\
\hline Cukup & 22 & 26,8 \\
\hline Kurang & 46 & 56,1 \\
\hline Jumlah & 82 & 100,0 \\
\hline Pengetahuan Psikologgis & & \\
\hline Baik & 18 & 22,0 \\
\hline Cukup & 23 & 28,0 \\
\hline Kurang & 41 & 50,0 \\
\hline Jumlah & 82 & 100,0 \\
\hline
\end{tabular}


Berdasarkan tabel 2 diatas menunjukkan bahwa lebih dari setengah suami hamil (56,1\%), mempunyai pengetahuan kurang tentang perubahan fisiologis ibu hamil dan setengah suami hamil (50,0\%), mempunyai pengetahuan kurang tentang perubahan psikologi ibu hamil.

\section{PEMBAHASAN}

\section{Gambaran Pengetahuan Ibu Hamil} Tentang Perubahan Fisik Saat Hamil di wilayah kerja UPTD Puskesmas Beringin Raya Kota Bengkulu tahun 2016.

Hasil penelitian tentang pengetahuan ibu hamil tentang perubahan fisiologis saat hamil menunjukkan bahwa dari 82 ibu hamil diketahui bahwa lebih dari setengah ibu hamil $46(56,1 \%)$, mempunyai pengetahuan kurang, sebagian kecil ibu hamil 21 (25,6\%), memiliki pengetahuan baik dan sebagian kecil reponden $15 \quad(18,3 \%)$, mempuanyai pengetahuan cukup tentang perubahan fisiologis saat hamil.

Berdasarkan hasil penelitian dapat dijelaskan bahwa kecenderungan ibu hamil mempunyai pengetahuan yang kurang baik mengenai perubahan

fisiologis, keadaan ini dapat terjadi karena kurangnya informasi yang didapat oleh ibu hamil atau juga disebabkan rendahnya pendidikan maupun pengalam ibu menjalani kehamilan.

Berdasarkan hasil penelitian dapat dilihat bahwa jawaban pada pengetahuan tentang perubahan fisiologis di dapat responden yang paling banyak tidak diketahui oleh ibu hamil mengenai perubahan fisik antara lain adalah 63 (77\%) ibu tidak mengetahui pada usia berapa ibu hamil merasakan perutnya membesar $56(68 \%)$ ibu tidak mengetahui tentang penyebab sering kecing saat hamil $54(66 \%)$ ibu tidak mengerti penyebab sembelit.

Hasil penelitian Sulistiyani (2013), di BPM Anik Suroso Mojosongo Surakarta menunjukkan bahwa pengetahuan ibu hamil mengenai perubahan fisik saat kehamilan dalam kategori baik sebanyak responden 10 $(18,52 \%)$, Pengetahuan ibu hamil mengenai perubahan fisik saat kehamilan dalam kategori cukup sebanyak 39 (72,22\%), Pengetahuan ibu hamil mengenai perubahan fisik saat kehamilan dalam kategori kurang sebanyak $5(9,26 \%)$.

Menurut Helen, (2007), wanita selama kehamilannya memerlukan waktu untuk beradaptasi dengan berbagai perubahan yang terjadi dalam dirinya. Perubahan-perubahan yang terjadi selama kehamilan umumnya menimbulkan ketidaknyamanan dan kekhawatiran bagi sebagian besar ibu hamil. Perubahan pada ukuran tubuh, bentuk payudara, pigmentasi kulit, serta pembesaran abdomen secara keseluruhan membuat tubuh ibu hamil tersebut tampak jelek dan tidak percaya diri. Kekhawatiran dan ketakutan ini sebenarnya tidak berdasar, untuk itu ibu hamil memerlukan nasihat dan saran khususnya dari bidan dan dokter yang dapat menjelaskan perubahan yang terjadi selama kehamilan sehingga ibu tidak khawatir dengan perubahan yang dialaminya.

Perubahan pada ukuran tubuh, bentuk payudara, pigmentasi kulit, serta pembesaran abdomen secara keseluruhan membuat tubuh ibu hamil tersebut tampak jelek dan tidak percaya diri. Kekhawatiran dan ketakutan ini sebenarnya tidak berdasar, untuk itu ibu hamil memerlukan nasihat dan saran khususnya dari bidan dan dokter yang dapat menjelaskan perubahan yang terjadi selama kehamilan sehingga ibu tidak khawatir dengan perubahan yang dialaminya. (Intan, 2015)

Menurut Riswandi (2009), demi meningkatkan pengetahuan ibu hamil program pendidikan kesehatan kepada ibu hamil melalui penyuluhan-penyuluhan tentang perubahan fisiologis dan psikologis yang terjadi selama kehamilan, sangat diperlukan sehingga ibu hamil memiliki pengetahuan mengenai perubahan-perubahan pada masa kehamilan, dengan demikian ibu hamil dapat membedakan perubahan yang normal dan tidak normal (patologis)

Berdasarkan hasil penelitian ini dapat 
simpulkan bahwa pengetahuan ibu hamil mengenai perubahan fisiologis merupakan hal yang sangat penting bagi ibu, karena dengan pengetahuan yang baik dari ibu dapat menyebabkan kecemasan dengan perubahan yang ada pada ibu hamil. Karena ibu hamil seringkali merasa khawatir atau takut jika janinnya yang dilahirkannya tidak normal.

2. Gambaran pengetahuan ibu hamil tentang perubahan psikologis saat hamil di Wilayah Kerja UPTD Puskesmas Beringin Raya Kota Bengkulu

Hasil penelitian ini menunjukkan bahwa pengetahuan ibu hamil tentang perubahan psiologis diketahui bahwa dari 82 terdapat hampir sebagian ibu hamil 38 (46,3\%), mempunyai pengetahuan baik, hampir sebagian ibu hamil 28 (34,1\%) memiliki pengetahuan cukup dan sebagian kecil 16 (19,5\%), memiliki pengetahuan kurang tentang perubahan psikologi saat hamil.

Berdasarkan hasil penelitian dapat dilihat bahwa jawaban responden yang paling banyak tidak diketahui oleh ibu tentang perubahan psikologi antara lain adalah, 38 (46\%) ibu tidak mengetahui jika saat hamil, ibu akan merasakan masalah psikologis merasa kehilangan perhatian suami, 31 (38\%) ibu tidak mengetahui jika saat hamil akan mengalami perasaan mudah terluka (sensitif) dan 29 (35\%) ibu tidak mengetahui jika ibu merasa sedih karena terpisah dari bayinya.

Hasil penelitian Harahap (2008) Berdasarkan kategori pengetahuan ibu hamil tentang perubahan psikologis diketahui sebanyak $31 \mathrm{ibu}$ hamil $(55,4 \%)$ mempunyai pengetahuan cukup tentang perubahan psikologis yang terjadi pada masa kehamilan, sedangkan $25 \mathrm{ibu}$ hamil lainnya (44,6\%) mempunyai pengetahuan baik.

Berdasarkan hasil penelitian dapat dijelaskan bahwa kecenderungan ibu hamil mempunyai pengetahuan baik mengenai perubahan perubahan psikologis saat menjalani kehamilan hal ini menggambarkan bahwa ibu hamil sudah banyak yang memahami tentang perubahan-perubahan psikologi terjadinya saat hamil. dengan baiknya pengetahuan ibu tentang perubahan psikologi ini akan berdampak positif kepada tingkat kecemasan ibu hamil karena ibu sudah mengerti dan memahami bahwa perubahanperubahan tersebut merupakan hal yang wajar terjadi pada ibu hamil.

Menurut Manuaba (2009), adanya perubahan hormon, hampir seluruh ibu hamil secara emosional labil dan cenderung goyah, reaksi ekstrim pada hal-hal yang kecil, menangis, merasa kurang percaya diri dan mudah panik. Bahkan pada kehamilan yang paling positif, ibu hamil akan mengalami depresi, rasa takut dan bingung. Banyak anggapan perubahan psikologis yang terjadi pada ibu hamil akibat adanya beberapa perubahan biologi. Kejadian dan proses psikologis ini diidentifikasi pada tiap trimester kehamilan ibu. Setiap trimester kehamilan, biasanya ibu hamil merasakan perubahan emosional yang labil dan semakin memasuki trisemester ketiga kecemasan dan ketegangan semakin meningkat, dengan adanya pengetahua yang baik maka ibu hamil dapat meminimalkan kecemasan tersebut.

\section{Gambaran Pengetahuan Suami Tentang Perubahan Fisik Saat Hamil di wilayah kerja UPTD Puskesmas Beringin Raya Kota Bengkulu tahun 2016.}

Hasil penelitian ini menunjukkan bahwa dari 82 suami ibu hamil terdapat setengah suami hamil $(56,1 \%)$, mempunyai pengetahuan kurang, hampir sebagian suami $(26,8 \%)$, mempunyai pengetahuan cukup dan sebagian kecil suami (17,1\%), memiliki pengetahuan baik tentang perubahan fisiologis pada ibu hamil.

Berdasarkan hasil penelitian dapat dilihat bahwa jawaban responden yang paling banyak tidak diketahui oleh suami ibu hamil mengenai perubahan fisik antara lain adalah $54(66 \%)$ suami tidak mengetahui berapa $\mathrm{Kg}$ kenaikan berat badan ibu pada usia 8-16 minggu /1-2 bulan, 52 (63\%) suami tidak mengetahui penyebab ibu hamil sering terjadi mual muntah di pagi hari, 53 (65\%) suami 
tidak mengetahui penyebab sering kencing pada ibu hamil.

Hasil penelitian Ningrum (2011), menunjukkan bahwa tingkat pengetahuan suami terhadap perubahan fisiologis istri selama kehamilan di klinik bersalin bidan Nurhalma menunjukkan bahwa mayoritas responden suami memiliki tingkat pengetahuan cukup sebanyak 28 orang $(49,1 \%)$ dan minoritas responden suami memiliki pengetahuan baik sebanyak 10 orang $(17,5 \%)$.

Berdasarkan hasil penelitian ini dapat dijelaskan bahwa pengetahuan suami mengenai perubahan fisik pada ibu hamil pada kategori kurang, namun masih banyak juga suami yang mempunyai pengetahuan cukup mengenai perubahan fisik, dengan keadaan ini dapat menjadi faktor kurangnya penan suami dalam mendukung ibu hamil dalam menjalani kehamilannya secara sehat. Masih banyaknya suami yang mempunyai pengetahuan kurang hal ini dapat disebabkan banyak hal seperti kurangnya informasi yang didapatkan tentang perubahan fisik selama kehamilan dari orang yang tidak tepat. Hal ini didukung oleh Mubarak (2012), yang menyatakan bahwa kemudahan memperoleh informasi dapat membantu mempercepat seseorang untuk memperoleh pengetahuan yang baru.

Menurut Wawan (2010), pengetahuan merupakan hasil dari tidak tahu menjadi tahu, ini terjadi karena seseorang melakukan penginderaan terhadap suatu obyek tertentu. Sebagian besar pengetahuan manusia diperoleh melalui mata dan telinga. Pengetahuan merupakan faktor penting dalam menentukan perilaku seseorang karena pengetahuan dapat menimbulkan perubahan persepsi dan kebiasaan masyarakat. Meningkatnya pengetahuan juga dapat merubah persepsi masyarakat tentang penyakit. Meningkatnya pengetahuan juga dapat mengubah perilaku masyarakat dari yang negatif menjadi positif, selain itu pengetahuan juga membentuk kepercayaan.

\section{Gambaran Pengetahuan Suami Tentang Perubahan Psikologis Saat Hamil di wilayah kerja UPTD Puskesmas Beringin Raya Kota Bengkulu tahun 2016.}

Hasil penelitian tentang pengetahuan suami tentang perubahan psikologis diketahui bahwa dari 82 responden terdapat hampir sebagian suami $(50,0 \%)$, mempunyai pengetahuan kurang, hampir sebagian suami (28,0\%), mempunyai pengetahuan cukup dan sebagian kecil suami (22,0\%), mempunyai pengetahuan baik tentang perubahan psikologi ibu hamil.

Berdasarkan hasil penelitian dapat dilihat bahwa jawaban responden yang paling banyak tidak diketahui oleh suami ibu hamil mengenai perubahan psikologis pada ibu hamil antara lain adalah 49 (60\%) suami tidak mengetahui perubahan psikologis ibu merasa sedih karena terpisah dari bayinya, 47 (57\%) suami tidak mengetahui ibu hamil mengalami perubahan psikologis mengalami takut akan rasa sakit dan bahaya fisik yang akan timbul saat melahirkan dan 44 (54\%) suami tidak mengetahui ibu hamil akan mengalami perubahan psikologis merasa kehilangan perhatian saat masa kehamilan.

Tingkat pengetahuan suami tentang perubahan psikologis pada istri yang sedang hamil dapat mempengaruhi motivasi, rasa optimis suami untuk mencari tahu perubahanperubahan yang dialami istri saat hamil. Suami juga akan berperan untuk selalu memberikan dukungan kepada istri selama kehamilannya baik biologis maupun psikologis.

Sedangkan pada pengetahuan yang kurang baik dari suami juga dapat dipengaruhi oleh lingkungan maupun pengalaman dari suami, seperti menurut menurut Notoadmodjo (2010), lingkungan juga mempengaruhi pengetahuan misalnya lingkungan pekerjaan, karena lingkungan memiliki fungsi sebagai alat pergaulan sosial dan bertukar informasi yang dalam hal ini mengenai Perubahan fisiologis dan perubahan psikologis isteri selama kehamilan. 
Berdasarkan hasil penelitian ini dan teori yang telah dikemukakan dapat disimpulkan bahwa pengetahuan seorang suami merupakan hal yang sangat penting dimiliki suami, karena dengan adanya pengetahuan yang baik dari suami akan menimbulkan rasa perhatian yang lebih kepada istri dalam menjalani kehamilan karena suami lebih mengerti perubahanperubahan yang terjadi saat istri hamil. Selain itu dengan adanya pengetahuan yang baik dari suami mengenai perubahan fisik dan psikologi saat hamil pada istrinya akan meningkatkan partisipasi suami dalam kesehatan reproduksi terutama dalam pemeliharaan kesehatan dan kelangsungan hidup ibu dan anak, serta berperilaku seksual yang sehat dan aman bagi dirinya, istri dan keluarganya.

\section{KESIMPULAN}

Dari hasil penelitian tentang gambaran pengetahuan ibu dan suami tentang perubahan fisik dan psikologis saat hamil di Wilayah Kerja UPTD Puskesmas Beringin Raya Kota Bengkulu Tahun 2016, dapat ditarik kesimpulan sebagai berikut:

a. Lebih dari setengah ibu hamil mempunyai pengetahuan kurang tentang perubahan fisiologis saat hamil.

b. Hampir sebagian ibu hamil mempunyai pengetahuan baik tentang perubahan psikologi saat hamil.

c. Lebih dari setengah suami ibu hamil, mempunyai pengetahuan kurang tentang perubahan fisiologis ibu hamil.

d. Setengah suami ibu hamil, mempunyai pengetahuan kurang tentang perubahan psikologi ibu hamil.

\section{SARAN}

Berdasarkan hasil penelitian yang telah dilakukan maka peneliti memberi saran kepada:

\section{Teoritis}

a. Akbid Dehasen Bengkulu

Diharapkan bagi institusi Akbid Dehasen Bengkulu dapat meningkatkan pembelajaran bimbingan dan konseling khususnya tentang memberikan asuhan pada ibu hamil kepada mahasiswa agar mahasiswa lebih mahir dalam memberikan asuhan pada ibu hamil.

b. Bagi peneliti selanjutnya

Kepada peneliti selanjutnya diharapkan dapat mengembangkan penelitian ini dengan melihat hubungan antara pengetahuan suami dengan peran serta suami dalam mendukung istri dalam menjalani masa hamil menggunakan desain penelitiaan yang berbeda seperti desain croos sectional memperluas ruang lingkup penelitian agar didapat hasil yang lebih baik lagi.

2. Praktis

a. Puskesmas Beringin Raya Kota
Bengkulu.

Diharapkan kepada pihak Puskesmas Beringin Raya Kota Bengkulu dapat lebih meningkatkan dalam memberikan penyuluhan kepada ibu hamil sehingga meningkatkan pengetahuan ibu hamil, serta dapat mengikut sertakan suami dalam pendidikan kesehatan pada ibu hamil sehingga dapat berparisipasi mendukung istri dalam menjalani kehamilan dengan aman.

\section{b. Ibu Hamil dan Suami}

Kepada ibu hamil dan suami diharapkan dapat memahami tentang perubahan fisiologis maupun psikologis pada masa hamil, sehingga dalam menjalani masa kehamilan ibu hamil dan suami akan lebih mengerti tentang perubahan normal dan tidak normalnya kehamilan. 


\section{DAFTAR PUSTAKA}

Arikunto.2010. Prosedur Penelitian Suatu Pendekatan Praktek. Jakarta: Rineka Cipta

Blobak,L.J. 2004.Buku Ajar Keperawatan Maternitas. Edisi 4.jakarta.penerbit buku kedokteran EGC

Cunningham.2007. Panduan Lengkap Kebidanan.jogyakarta :Nuha medika.

Depkes RI.2010.proposal kesehatan indonesia 2008.jakarta: Depkes ri

Kusmiyati, dkk, 2009. Perawatan Ibu Hamil. Yogyakarta: Penerbit Fitramaya

Mansur, Herawati. 2009. Psikologi Ibu dan Anak untuk Kebidanan. Jakarta: Salemba Medika

Manuaba I.B.G. 2009. Pengantar Kuliah Obstetri. Jakarta: EGC

Mufidaturrosida. 2015. Faktor-Faktor yang Berhubungan dengan Kesiapan Persalinan. Masters thesis, Universitas Negeri Sebelas Maret.

Notoadmodjo. (2003). Pendidikan Perilaku Kesehatan.Jakarta: PT Rineka Cipta 2010.Metodologi Penelitian

kesehatan. Jakarta: Rineka Cipta. 2010.Ilmu kesehatan Masyarakat Ilmu dan Seni. Jakarta: PT. Rineka Cipta

Nursalam.2008.Konsep

Penerapan Metodelogi Penelitian Dan Ilmu Keperawatan. Jakarta: Salemba Medika.

Pratiwi, dkk. 2007. Biologi Untuk SMA Kelas $X I$. Jakarta: Erlangga

Prawiroharjo, S. 2006. Ilmu Kebidanan. Jakarta: Bina Yayasan Pustaka

Prawirohardjo, S., 2010. Ilmu Kebidanan. Jakarta: PT Bina Pustaka Sarwono Prawirohardjo

Sunarsih. 2011. Asuhan Kehamilan untuk Kebidanan. Jakarta : Saleman Medika

Solihah. 2001.Panduan Lengkap Hamil Sehat. Yogyakarta:DIVA Press

Sulistyawati. 2009. Asuhan Kebidanan Pada Masa Kehamilan. Jakarta: Salemba Medika.

Sulistyawati. 2013. Asuhan Kebidanan Pada
Masa Kehamilan. Jakarta: Penerbit Salemba Medika.

Sulistyawati.2009. Asuhan Kebidanan Pada Masa Kehamilan. Jakarta: Selemba Medika.

Sunarsih. 2011. Asuhan Kehamilan untuk Kebidanan. Jakarta : Saleman Medika. 